Pesq. Vet. Bras. 35(10):863-870, outubro 2015 DOI: 10.1590/S0100-736X2015001000008

\title{
Expressão da enzima indoleamina-2,3-dioxigenase em truta arco-íris (Oncorhynchus mykiss) ${ }^{1}$
}

\author{
Fernanda Cardoso ${ }^{2 *}$, Carlos E. Malavasi Bruno², Cristiane C. Ramos², Andre L.V. Conrado², \\ Yara A. Tabata ${ }^{3}$, Juliana Shimara Pires Ferrão² e José Roberto Kfoury Junior ${ }^{2}$
}

\begin{abstract}
Cardoso F., Malavasi Bruno C.E., Ramos C.C., Conrado A.L.V., Tabata Y.A., Pires Ferrão J.S. \& Kfoury Junior J.R. 2015. [Expression of the enzyme indoleamine-2,3-dioxygenase in Rainbow Trout (Oncorhynchus mykiss).] Expressão da enzima indoleamina-2,3-dioxigenase em truta arco-íris (Oncorhynchus mykiss). Pesquisa Veterinária Brasileira 35(10):863-870. Setor de Anatomia dos Animais Domésticos e Silvestres, Faculdade de Medicina Veterinária e Zootecnia, Universidade de São Paulo, Av. Prof. Dr. Orlando Marques de Paiva 87, São Paulo, SP 05508-270, Brazil. E-mail: fefetkd@gmail.com

Indoleamine 2,3-dioxygenase (IDO) is an enzyme that catabolizes the amino acid tryptophan, leading to inhibition of T lymphocyte proliferation, whether by depletion of this amino acid in the environment, or by induction via the catabolites inducing apoptosis. In mammals, this enzyme acts on various conditions of the body such as pregnancy, infections, chronic inflammation, transplantation and tumors, acting in immune regulation. Recent studies have identified the presence of homologous molecules IDO lower phylogenetically related species, whose function appears to be confined to the tryptophan metabolism as an energy source. This study aimed to investigate the expression of IDO in blood cells and hematopoietic organs of rainbow trout by immunohistochemistry, seeking evidence that it could, this species is related to the immune system. The expression of IDO was observed in hematopoietic organs studied including head kidney that show labeling in interrenal cells and leukocytes; spleen, in which the marking restricted to a few leukocytes in the liver;, labeling was restricted to only certain cells within the blood vessels and the blood extensions can view the marking of some leukocytes including monocytes, lymphocytes and neutrophils. The predominance of IDO marking these tissues may constitute evidence that IDO identified in O. mykiss is related to the immune system in this species.
\end{abstract}

INDEX TERMS: Indoleamine 2,3-dioxygenase, rainbow trout, Oncorhynchus mykiss, leukocytes, hematopoietic organ.

RESUMO.- A indoleamina 2,3-dioxigenase (IDO) é uma enzima que cataboliza o aminoácido triptofano, levando à inibição da proliferação de linfócitos T, seja pela exaustão desse aminoácido no ambiente, ou pela indução via catabólitos induzindo-os a apoptose. Em mamíferos, esta enzima atua em diversas condições do organismo como a gestação, infecções, inflamações crônicas, transplantes e tumores, atuando na regulação imunológica. Estudos re-

\footnotetext{
${ }^{1}$ Recebido em 11 de março de 2015.

Aceito para publicação em 1 de setembro de 2015.

${ }^{2}$ Setor de Anatomia dos Animais Domésticos e Silvestres, Departamento de Cirurgia, Faculdade de Medicina Veterinária e Zootecnia, Universidade de São Paulo (USP), Av. Prof. Dr. Orlando Marques de Paiva 87, São Paulo, SP 05508-270, Brasil. *Autor para correspondência: fefetkd@gmail.com

${ }^{3}$ APTA - Estação Experimental de Salmonicultura, Parque Estadual, Campos do Jordão, SP 12460-000.
}

centes identificaram a presença de moléculas homólogas a IDO em espécies filogeneticamente inferiores, cuja função parece estar restrita ao metabolismo do triptofano como fonte de energia. Este estudo teve por objetivo averiguar a expressão da IDO em células sanguíneas e órgãos hematopoiéticos de truta arco-íris pela imuno-histoquímica, buscando evidências de que a mesma poderia, nesta espécie, estar relacionada ao sistema imune. A expressão de IDO foi observada nos órgãos hematopoiéticos estudados incluindo o rim cefálico que apresentou marcação em células interrenais e leucócitos; baço, na qual a marcação restringiu à alguns leucócitos; no fígado a marcação ficou limitada à apenas algumas células dentro dos vasos sanguíneos e nas extensões sanguíneas pode-se visualizar a marcação de alguns leucócitos como os monócitos, linfócitos e neutrófilos. A predominância da marcação da IDO nesses tecidos 
pode constituir uma evidência de que a IDO identificada na o. mykiss esteja relacionada ao sistema imunológico nessa espécie.

TERMOS DE INDEXAÇÃO: Indoleamina 2,3-dioxigenase, truta arco-íris, Oncorhynchus mykiss, leucócitos, órgãos hematopoiéticos.

\section{INTRODUÇÃO}

A truta arco-íris (Oncorhynchus mykiss), além de ser um pescado de alto valor comercial, é também considerada um modelo experimental importante e é amplamente utilizada em diversos centros de pesquisa.

Os peixes, de modo geral, dispõem de mecanismo de defesa inato e foram o primeiro grupo de vertebrados a desenvolver a imunidade adquirida (Garcia-Leme 1989). A imunidade inata envolve os leucócitos, que desenvolvem ações de inflamação e a fagocitose e é também composta por várias substâncias como as lisozimas, interferon, proteína $\mathrm{C}$ reativa, transferrina e lectina, que podem ser comumente encontradas no muco, soro e ovo dos peixes e inibem o crescimento de microrganismos infecciosos (Secombes 1996, Yano 1996). A imunidade adquirida é mais específica e pode desencadear uma resposta humoral, mediada por anticorpos, ou uma resposta mediada por células, onde ambas proporcionam ao indivíduo proteção e memória imunológica (Shoemaker et al. 2001).

Os órgãos linfóides nos peixes são representados pelo rim cranial ou cefálico, órgão primário diferenciador de células, além de ser o principal tecido hematopoiético, possuindo função endócrina e imunológica e atuando na produção de anticorpos e catecolaminas (Zapata 1981). 0 fígado apresenta um papel semelhante no que se referem ao sistema imunológico de mamíferos, suas funções incluem a assimilação de nutrientes, produção de bile, desintoxicação e manutenção da homeostase metabólica, que inclui processamento de carboidratos, proteínas, lipídios e vitaminas, pois o fígado é responsável pela produção de proteína reativa, que compõe a cascata de eventos desencadeada pelo sistema complemento desempenhando um papel importante na síntese de proteínas plasmáticas (Fletcher 1981).

A indoleamina 2,3-dioxigenase (IDO) é uma enzima oxigenase que cataboliza o aminoácido triptofano, levando à inibição da proliferação principalmente de linfócitos T, seja pela exaustão desse aminoácido no microambiente ou pela indução via catabólitos a apoptose (Barksdale et al. 2004). A IDO em mamíferos é expressa em diversos tecidos como o cerebral, pulmonar, cardíaco, renal e intestinal (Takikawa et al. 1986) e também por alguns tipos celulares, como monócitos in vitro, células tumorais (Munn \& Sharma 2002) e por células trofoblásticas (Munn et al. 1998). Estudos in vitro vêm demonstrando que a expressão da IDO por monócitos que derivam os macrófagos e células dendríticas podem inibir a proliferação de células $\mathrm{T}$ (Munn et al. 2004).

A IDO é reconhecida como um autêntico regulador da imunidade em diversas condições do organismo que se utilizam de mecanismos de evasão do sistema imunológico, como por exemplo, a gestação, infecções, alergias, in- flamações crônicas, transplantes e tumores (Pallota et al. 2011).

Os conhecimentos em imunologia de peixes teleósteos ainda não estão totalmente elucidados se comparados aos dos mamíferos, portanto estudos nesta área tornam-se uma ferramenta importante que poderá auxiliar na compreensão dos mecanismos do sistema imunológico da truta arcoíris. Informações sobre a presença ou função dessa enzima em peixes são escassas e, uma vez que filogeneticamente esta classe de animais sofreu mudanças significativas na evolução do sistema imunológico, formulou-se a hipótese de que, se confirmada à presença da IDO em truta arco-íris (Oncorhynchus mykiss), esta poderia ser um forte indício de sua participação na resposta imune nesses animais. Dessa forma, como primeiro passo para comprovar tal hipótese, este trabalho avaliou a presença da IDO em células sanguíneas e órgãos hematopoiéticos de truta arco-íris.

\section{MATERIAL E MÉTODOS}

Os peixes utilizados foram fornecidos pela Estação Experimental de Salmonicultura "Dr. Ascânio Faria" da Apta Regional Vale do Paraíba da Secretaria de Agricultura e Abastecimento do Estado de São Paulo. Todos os procedimentos realizados neste trabalho estão de acordo com a Comissão de Ética no uso de animais da FMVZ-USP, certificado n. 2594/2012.

Cinquenta trutas (Oncorhynchus mykiss), fêmeas de um ano e meio de idade e de aproximadamente $1 \mathrm{~kg}$, foram divididas em dez grupos de cinco animais. Os peixes foram mantidos em tanques de fibra de vidro, contendo cerca de 1500 litros de água corrente, abastecimento e escoamento independentes, sob condições naturais de fotoperíodo. Durante o estudo, os animais receberam ração comercial extrusada administrada três vezes ao dia ad libitum.Os peixes foram anestesiados por imersão em solução aquosa de benzocaína na proporção de 1:10.000 para punção sanguínea e 1:500 no momento da eutanásia para a retirada dos órgãos. Inicialmente, a benzocaína foi dissolvida previamente em álcool etílico (qsp) e, em seguida, diluída na água (Wedemeyer 1970; Matushima 1988). A manipulação dos peixes só foi iniciada após os mesmos apresentarem diminuição dos movimentos operculares e perda de equilíbrio (Coyle et al. 2004). As truta foram retiradas da água e pesadas em uma balança (Sartorius BP 8100).

0 sangue foi coletado pela punção da veia caudal utilizando-se seringas heparinizadas. Uma alíquota foi utilizada para a confecção das extensões sanguíneas em lâminas silanizadas (Starfrost ${ }^{\circledR}$ ) e o restante foi submetido à centrifugação 306 x g por dez minutos. Desprezou-se o sobrenadante e o tampão leucocitário foi utilizado para a confecção dos extensões sanguíneas (esfregaço sanguíneo). Para a análise morfológica das células sanguíneas foi utilizada a coloração de May-Grünwald-Giemsa-Wright (Tavares-Dias \& Moraes 2004). Após a retirada do rim cefálico foi realizado um imprint em lâminas de vidro para averiguar a presença de células sanguíneas. Tanto as extensões sanguíneas quanto os imprints foram fixados em metanol por cinco minutos.

Após a coleta de sangue e eutanásia das truta, amostras de rim cefálico, baço e fígado, foram coletadas e fixadas em paraformaldeído 4\%, pH 7,2.

Para a imuno-histoquímica as lâminas silanizadas contendo as extensões sanguíneas e o imprint do rim cranial, foram submetidas ao bloqueio da atividade da peroxidase endógena com solução de peróxido de hidrogênio a 3\% diluído em metanol, e o bloqueio das reações inespecíficas foi realizado com leite em pó a 5\%, e então incubadas em câmara úmida overnight com o anticor- 
po Anti-IDO policlonal NB 100-2459 Novus Biologicals, (USA) na concentração de 1:100. Após lavagem com PBS, as lâminas foram novamente incubadas com anticorpo secundário HRP-Link (Dako Envision System HRP, K1390) e revelados em solução cromógena de diaminobenzidina (DAB, 3.3'- diaminobenzidine, Sigma) por 5 minutos. Por fim, os cortes foram contra-corados com May-Grünwald-Giemsa-Wright (Millipore) (Tavares-Dias \& Moraes 2004), lavados abundantemente em água corrente e desidratados em etanol em concentração crescente. A montagem das lâminas foi feita com resina Permount ${ }^{\circledR}$ (Fischer Scientific).

As células contendo as extensões sanguíneas foram contadas (x 5000 células) em campos escolhidos aleatoriamente com o auxílio de um microscópio óptico Olympus BX60 (Japão) com câmera fotográfica AxioCam HRc Zeiss ${ }^{\circledR}$ (USA). As células com marcação positiva para a imuno-histoquímica foram contadas com o auxílio de um contador manual e os resultados foram registrados como células positivas, num aumento de 100x $\left(20 \mu \mathrm{m}^{2}\right)$.

As análises estatísticas para as extensões sanguíneas foram realizadas com o teste t-student, e teste de Qui-quadrado (Snedecor \& Cochran 1974). Foi utilizado o software InStat (La Jolla CA, USA).

Os tecidos colhidos, após a passagem pelos álcoois e hidratação em água destilada, foram submetidos à recuperação antigênica por forno micro-ondas em potência máxima durante 15 minutos com as lâminas incubadas em solução tampão citrato de sódio a $10 \mathrm{M}, \mathrm{pH}$ 6,0. A solução de peróxido de hidrogênio a 3\% diluído em metanol foi utilizada para bloquear a ação da peroxidase endógena, e para o bloqueio das reações inespecíficas foi utilizado leite em pó a 5\%. Por fim, as amostras foram incubadas com os anticorpos primários na concentração 1:100 em câmara úmida overnight em geladeira. No dia seguinte, as lâminas foram lavadas em PBS pH 7,4 e incubadas com anticorpo secundário HRP-Link (DAKO) por 30 minutos a temperatura ambiente. Após a incubação, as lâminas foram lavadas em PBS 7,4. A reação imune foi revelada com solução cromógena de diaminobenzidina (DAB, 3.3'diaminobenzidine, Sigma) por cinco minutos. Os cortes foram lavados em água corrente por dez minutos, contracorados com Hematoxilina de Harris (HE), lavados em água corrente e desidratados em etanol. A montagem das lâminas também foi realizada com resina Permount ${ }^{\circledR}$.

As reações obtidas durante a imuno-histoquímica tiveram controles positivo G (+) tumor de mama canino (controle da amostra) e cólon de camundongo (para o controle do anticorpo) e negativo G (-) para confirmar a reação das mesmas. Para o controle negativo a incubação foi realizada em PBS com eliminação do anticorpo primário. Após a imuno-histoquímica as lâminas foram observadas com auxílio do microscópio óptico Axioscópio Zeiss $^{\circledR}$ e os resultados foram analisados em um microcomputador com programa de mensuração específico KS-400 Zeiss ${ }^{\circledR}$ num aumento de $40 \mathrm{x}\left(50 \mu \mathrm{m}^{2}\right)$. Para a realização da mensuração, durante o protocolo final da imuno-histoquímica, não foi utilizado nenhum tipo de contra-coloração (hematoxilina), evidenciando assim somente os tecidos com marcação positiva para receptores de IDO. Para o teste de Western Blot as proteínas foram extraídas e quantificadas a partir de tecidos do rim cefálico, baço, fígado e do tampão leucocitário, que foram previamente pesados e colocados em eppendorfs de 1,5ml contendo $400 \mu \mathrm{l}$ de $2 \mathrm{X}$ Sample Buffer $400 \mu \mathrm{l}$ de $1 \mathrm{X}$ Working Solution e $40 \mu \mathrm{l}$ de cocktail de inibidor de protease (P2714 Sigma-Aldrich). Em seguida esses tecidos foram processados utilizando um sonicador (QSonica, Q125) a $4^{\circ} \mathrm{C}$. As amostras de tecido foram centrifugadas por 15 minutos, a $4^{\circ} \mathrm{C}$ e 202xg; o sobrenadante foi transferido para um eppendorf armazenado em gelo. 0 controle positivo da reação foi realizado utilizando amostras de tumor mamário de cão.A quantificação das proteínas foi estimada utilizando o reagente BioRad Protein Assay pelo método de Bradford (BioRad Laboratories, Hercules CA, USA), sendo que $10 \mu \mathrm{l}$ das amostras foram diluídos em $90 \mu \mathrm{l}$ de solução de $1 X$ Working Solution, sendo que $10 \mu$ desta solução foram adicionados a $990 \mu \mathrm{l}$ do reagente de Bradford, diluído em água destilada (1:5). A curva padrão foi feita com soro albumina bovina adicionada ao reagente de Bradford em diferentes concentrações. As amostras foram incubadas por 5 minutos e quantificadas em um Biofotômetro (BioPhothometer Plus, Eppendorf, Germany). Após a preparação do gel inferior (Resolving Gel) e do gel superior (Stacking gel), as amostras adquiridas após a extração e quantificação, foram diluídas em Sample Buffer (Azul de bromofenol, glicerol, Tris-HCL, $\beta$ Mercaptoetanol, SDS e DTT) e submetidas à desnaturação proteica. As amostras diluídas foram colocadas em eppendorfs de $0,2 \mathrm{ml}$ no banho seco durante 10 minutos a $95^{\circ} \mathrm{C}$ (Termociclador Mastercycler pró S Eppendorf Germany). Em seguida, foi adicionado $15 \mu \mathrm{L}$ da amostra em cada poço, sendo que o primeiro poço foi preenchido com $10 \mu \mathrm{L}$ com o marcador molecular (Precision Plus Protein Kaleidoscope Prestained Standards \#1610324, Bio-Rad), e as amostras foram corridas em uma cuba de eletroforese (Bio-Rad), por duas horas e meia, começando com $45 \mathrm{~V}$, no gel superior e posteriormente a $110 \mathrm{~V}$ no gel inferior. Após o término da corrida foram preparadas três cubas: A primeira contendo metanol, na qual a membrana de PVDF (Immun-Blot PVDF Membrane \#162-0177 Bio-Rad) ficou mergulhada por 5 minutos, para estabilizá-la; a segunda cuba com água destilada e a terceira cuba com tampão de transferência (buffer solução de uso). A transferência ocorreu com 120mA por 120 minutos. 0 bloqueio das reações inespecíficas foi realizado com leite em pó a 5\% (Skin Milk, Difco BD), por duas horas, e lavadas três vezes por cinco minutos cada com TTBS 1X, incubadas com os anticorpos primários: Anti-IDO policlonal (NB 100-2459 Novus Biologicals, USA) e o EB09548 policlonal anti-Indol (Everest Biotech, USA) overnight na concentração 1:200. No dia seguinte, após as lavagens com TTBS 1X, a membrana foi incubada com anticorpo secundário 1:2000 (Bovine anti goat IGg HRP, Santa Cruz), por duas horas em temperatura ambiente. Após a incubação com o anticorpo secundário, a membrana foi preparada para a revelação quimioluminescente ECL (ECL Plus Western Blotting Analysis System-RPN 2132, Amersham, GE Healthcare). A revelação foi realizada no aparelho ImageQuant 350 (GE Helthcare).

\section{RESULTADOS}

A especificidade da marcação do anticorpo utilizado para a IDO em truta foi validada pelo teste de Western blott, onde as bandas confirmam a presença da enzima IDO nas amostras S1 (sangue), R1, R2, R3 (rim cefálico) onde a expressão da enzima IDO obteve marcação bem próxima (exceto pela segunda banda que ficou com aproximadamente $25 \mathrm{kDa}$ ) ao peso molecular dos controles, amostras C1, C2, C3 (Fig.1A e B), de 45,3 kDa.

Houve a degradação das amostras F (fígado), e B (baço). Não foi possível identificar nenhuma reação positiva no fígado e o baço apresentou uma fraca reação. A mesma banda foi revelada de duas formas para melhor visualização (Fig.1B). Para obter um parâmetro utilizamos o controle endógeno $\mathrm{C} 1$ e C3. Podemos observar visíveis marcações de IDO no R4 (rim cefálico), B (baço), S2 (sangue) (Fig.1A).

Os resultados da imuno-histoquímica demostraram que houve marcação citoplasmática positiva para a IDO no 

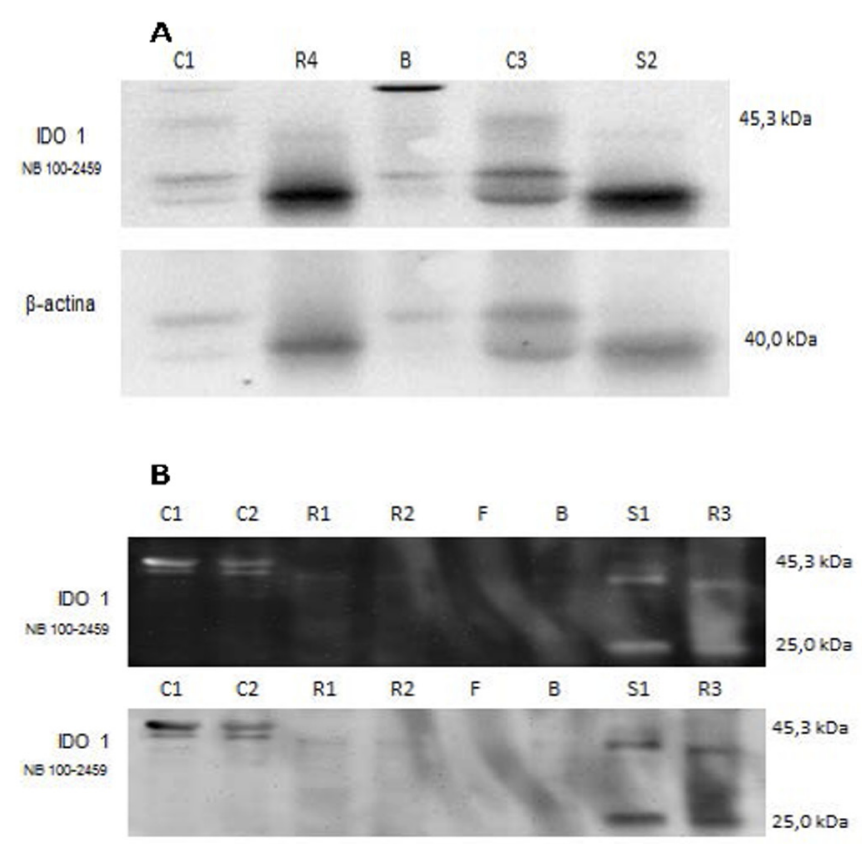

Fig.1. Detecção da enzima IDO pela técnica de western blot utilizando o anticorpo NB100-2459 (Novus Biologicals). Gel de poliacrilamida 13\% (SDS-PAGE). (A) C1 e C3, (controle endógeno da reação tumor de mama em cadelas, peso molecular com aproximadamente 45,3Kda e banda dupla). Em R4 (rim cefálico), B (baço), S2 (sangue) com visível marcação da IDO. (B) Marcação da expressão da enzima IDO todas com bandas duplas: para C1, C2, (tumor de mama em cadelas), S1 (sangue), R1, R2, (rim cefálico), R3 com uma marcação satisfatória. Degradação das Amostras: F (fígado), e B (baço). Revelação com ECL plus (Amershan).

baço de truta arco-íris (Oncorhynchus mykiss), sendo possível observar sua expressão em algumas células imaturas e linfócitos em vários estágios de maturação. Foi possível visualizar eritrócitos e trombócitos dispersos, porém estas células não foram marcadas positivamente (Fig.2A). No fígado a marcação ocorreu apenas em algumas células sanguíneas presentes dentro de alguns vasos sanguíneos, dentre as quais é possível visualizar linfócitos e células polimorfonucleares (Fig.2B). No rim cefálico identificamos marcações positivas para IDO, no tecido linfoide, leucócitos dispersos no tecido hematopoiético e em células sanguíneas em vários estágios de maturação dispersas dentro de vasos sanguíneos, houve marcação positiva de células do tecido interrenal e possível marcação de células cromafins, marcação de linfócitos dentro de um vaso sanguíneo (v) e a não marcação das células vermelhas. Observa-se a presença de melano-macrofagos, porém não é possível distinguir se estas células foram marcadas positivamente devido a sua coloração escura (Fig.2C). A imuno-histoquímica do imprint do rim cefálico, demonstrou marcação positiva de alguns leucócitos como os monócitos e linfócitos, e células indiferenciadas (Fig.2D). Foi possível identificar expressão de IDO nas extensões sanguíneas (Fig.3A,B,C,D) onde a contagem diferencial de leucócitos mostrou que, em um total de 50,000 células, $12,042 \%$ eram linfócitos e 0,756\% eram monócitos. Estas células apresentaram-se com valo- res médios de $12,7 \% \pm 0,1 \%$ células positivas, num total de $87,202 \% \pm 1,76 \%$ para células negativas, as quais corresponderam aos eritrócitos e trombócitos. Pela avaliação das diferenças dos valores de células positivas dos diferentes grupos com o teste do Qui-quadrado, o valor de 21,982 para Qui-quadrado e dependência entre a população de linfócito e monócito $(\mathrm{p}<0,01)$. $\mathrm{Na}$ avaliação das células positivas dos grupos pelo teste t-student, os valores médios de $602,1 \pm 202,2$ para os linfócitos positivos $(\mathrm{p}<0,01)$ e $37,8 \pm 20,1$ monócitos positivos $(\mathrm{p}=0,25)$ foram estatisticamente significativos. As células polimorfonucleares (majoritariamente neutrófilos), obtiveram valores muito próximos a zero e não foi considerado pelos testes de Qui-quadrado e t-student, sendo possível calcular somente a

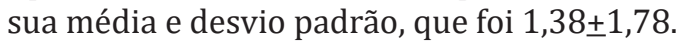

\section{DISCUSSÃO}

Neste trabalho foi possível evidenciar a expressão da indoleamina 2,3-dioxigenase (ID01) em linfócitos, monócitos e neutrófilos, bem como a marcação em alguns tecidos hematopoiéticos como o baço, fígado e o rim cefálico, pela imuno-histoquímica e western blot.

A detecção da IDO pelo western blotting confirmou a especificidade do anticorpo utilizado em marcar a IDO em truta. As bandas encontradas próximas a 45,3 kDa são compatíveis com as especificações do anticorpo e da literatura (Thomas et al. 1999) que afirmam que a IDO é uma oxigenasse monomérica com peso molecular que varia entre 40 a $43 \mathrm{kDa}$. A presença de bandas duplas nas amostras de células sanguíneas e rim cefálico presentes tanto nas amostras quanto nos controles são explicadas nas especificações do anticorpo que mostra que o cálculo do peso molecular está de acordo com NP_002155.1, e que ambas as bandas detectadas foram bloqueadas por incubação com sucesso com o peptídeo imunizante (e os resultados do BLAST com a sequência de peptídeo imunizante não identificou qualquer outra proteína para explicar as bandas adicionais). Este fato pode estar relacionado com o anticorpo ser policlonal e apresentar maior reatividade ou reação cruzada com outras espécies, como a truta arco-íris que, está bem distante das espécies reativas para o anticorpo. A banda dupla também foi obtida no experimento de Yuasa et al. (2007), onde a estrutura dos genes da ID01 e da IDO2 são bem conservados e em mamíferos e são apresentados em um arranjo paralelo no mesmo cromossomo.

A IDO2 (proto- IDO) existe não somente em mamíferos, mas também em vertebrados inferiores, mas nenhum gene correspondente a ID01 dos mamíferos foi encontrada nos genomas da galinha ou do zebra-fish, diferentemente de nossos resultados que mostraram a expressão da ID01 em células sanguíneas e rim cranial de truta arco-íris. Em humanos a expressão da ID02 não é tão onipresente como a da ID01, no entanto a ID02-mRNA pode ainda ser detectada no fígado, intestino, baço, placenta, timo, pulmão, cérebro, rim e cólon. A ID01 e a IDO2 de mamíferos (rato) e ID02 de sapos e peixes também foram expressas em células mamíferas intactas. Yuasa et al. (2011) sugere também que a IDO de mamífero é derivada de uma proto-IDO, e que o surgimento ocorreu antes da divergência dos marsupiais 
e dos mamíferos placentários. 0 gene que provavelmente originou a IDO pode ser encontrado em bactérias e em fungos, onde foram descobertos três tipos de IDO (Yuasa \& Ball 2012), sendo que sua função está relacionada à obtenção de NAD+ (nicotinamida-adenina-dinucleotídeo) via quinurenina e exerce mesma função da TDO (triptofano 2,3-dioxigenase) em mamíferos, este fato poderia sugerir que a ID01 em truta arco-íris é expressa em células e órgão ligados à imunidade assim como o dos vertebrados superiores.

Em diversos outros grupos de vertebrados mais basais encontrou-se moléculas muito próximas em formato e função às IDOs dos mamíferos, sendo estas as consideradas proto-IDOs. A proto-IDO foi relatada em algumas espécies de peixes e aves (Yuasa \& Ball 2012). Desde as camadas mais basais da escala evolutiva, a sequência de aminoácidos da proto-IDO de vertebrados foi conservada sugerindo que ela poderia exercer uma função essencial até hoje nas espécies (Yuasa \& Ball 2012).
A árvore filogenética da IDO apresenta: proteínas relacionadas a IDO em moluscos, a ID01 sendo encontrada em monotremados, marsupiais e mamíferos superiores (camundongos e humanos) e a ID02 (proto-IDO), em anfíbios, peixes, aves, monotremados, marsupiais e mamíferos superiores.

A fraca expressão de ID02 do peixe pode estar relacionada com a grande distância filogenética entre o peixe (fonte de enzima) e humano (célula hospedeira) (Yuasa et al. 2009).

A dificuldade para detectar a expressão da IDO pela técnica do Western Blot em truta pode estar relacionada com a baixa expressão da IDO devida a maior distância filogenética em relação aos vertebrados superiores. A fraca marcação do baço pode estar relacionada a este fato, e a não marcação da banda de IDO do fígado pode ser explicada pelos achados de Yuasa et al. (2011), que sugeriram que a ID01 não é expressada no fígado e que mesmo após amplificar o cDNAs da ID01 de amostras do tecido hepático,

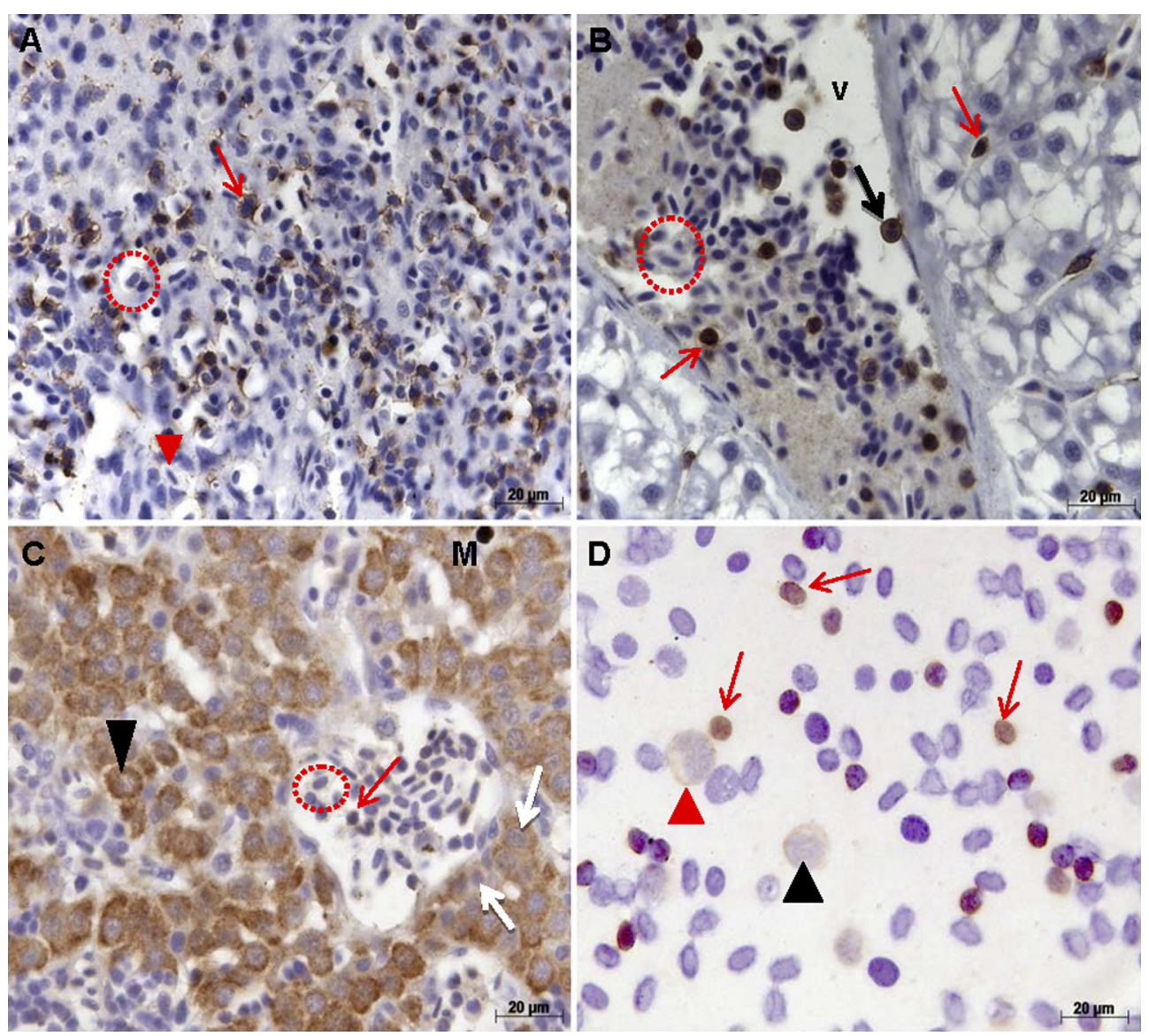

Fig.2. Expressão da IDO em tecidos hematopoiéticos de truta arco-íris pela técnica de imuno-histoquímica (Anti-IDO policlonal NB100 2459 Novus biological). Concentração 1:100. (A) No baço círculo vermelho indicando marcação negativa de um eritrócito, cabeça da seta vermelha indica um trombócito não marcado pela IDO, As setas indicam a marcação de leucócitos de vários tamanhos e em diferentes estágios de maturação. (B) No fígado das trutas arco-íris pode-se visualizar o círculo indicando eritrócitos dentro do vaso sanguíneo (v) não marcados pela IDO; seta preta indicando a marcação de células polimorfonucleares; seta vermelha indicando a marcação de linfócitos de vários tamanhos. (C) Rim cranial observa-se forte marcação de células do tecido interrenal indicada pela seta branca, ponta da seta mostrando uma possível célula cromafim, setas vermelhas indicando linfócitos dentro do vaso sanguíneo (v), M indicando um melano-macrófago e o círculo vermelho indicando um eritrócito não marcado. (D) Expressão da IDO no imprint do rim cranial de trutas arco-íris, seta vermelha (A) marcação positiva de um monócito. Cabeça da seta vermelha, indicam a marcação de linfócitos de vários tamanhos e diferentes estágios de maturação, e cabeça da seta preta indica uma célula indiferenciada. Contra- coloração: Hematoxilina de Harris (A,B,C), Giemsa (D), obj.100x. 


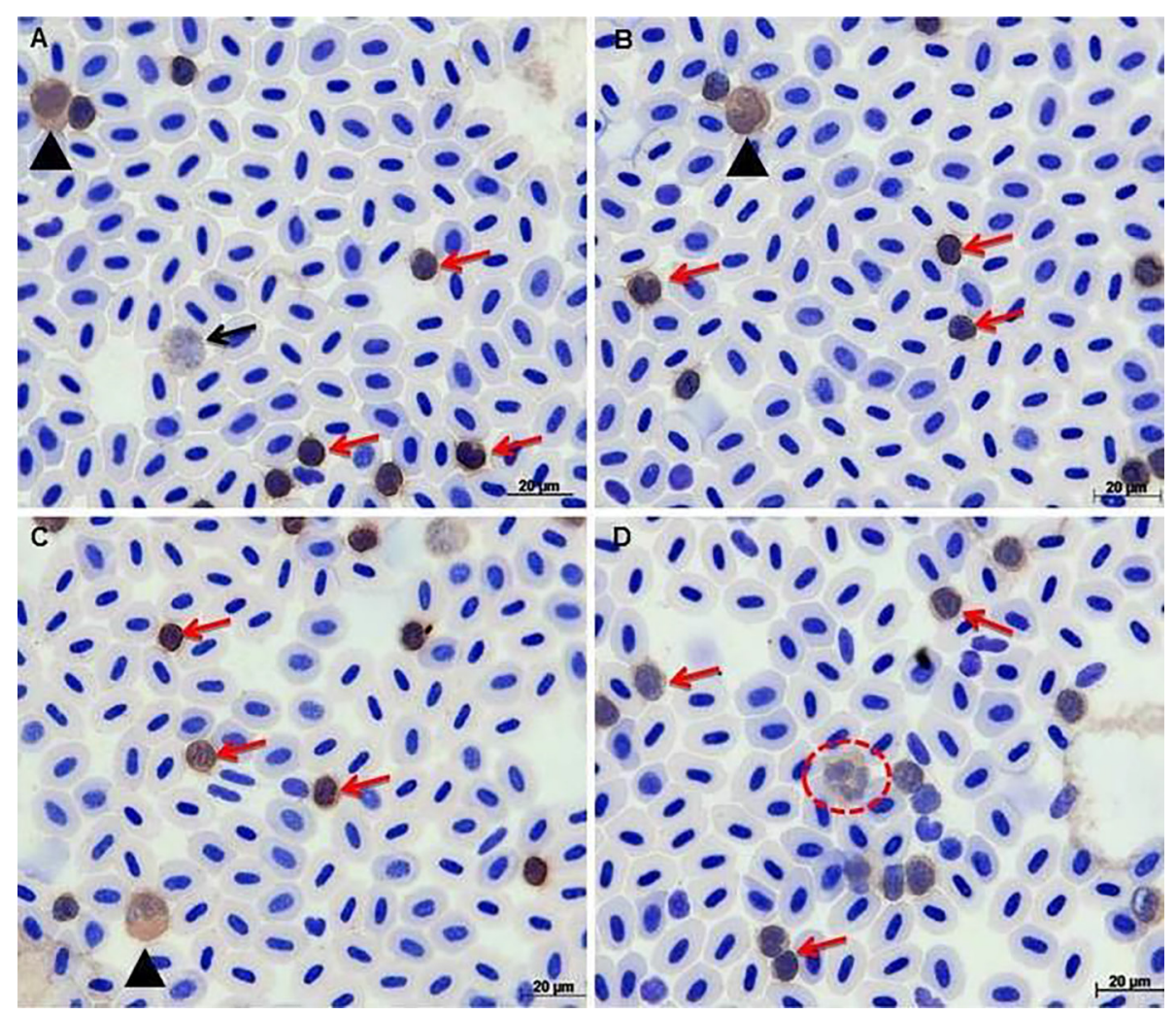

Fig.3. Marcação positiva para os receptores de IDO, utilizando o anticorpo Anti-IDO policlonal NB100 2459 Novus biologicals, (concentração 1:100). (A) Setas vermelhas indicam a marcação de linfócitos, a seta preta indica uma célula indiferenciada marcada positivamente pela IDO, a cabeça da seta preta mostra um monócito, (B) mostra um monócito (cabeça da seta preta) e variados linfócitos (setas vermelhas, Em (C) podemos visualizar um monócito cabeça da seta preta e vários linfócitos indicados pelas setas vermelhas. Em (D) pode-se visualizar a marcação de um neutrófilo (círculo vermelho) observa-se também a grande quantidade grânulos citoplasmáticos e núcleo segmentado, as setas vermelhas representam a marcação positiva da IDO no citoplasma dos linfócitos. Contra-coloração com Giemsa, obj.100x.

a quantidade da amostra do PCR da ID01 foi muito menor do que da ID02, sugerindo que as amostras amplificadas podem derivar dos leucócitos residuais nesse órgão. Em nossas observações, a expressão da IDO no baço e no fígado ficou limitada à marcação dos linfócitos no interior de pequenos vasos sanguíneos, que corroborando com a não evidenciação da ID01 através do western blot de amostras do fígado.

As marcações positivas da IDO no baço se mostraram nos leucócitos e não sendo evidenciadas no estroma esplênico. Este resultado corrobora com a afirmação de que as células IDO-positivas estão amplamente distribuídas em órgãos linfóides primários e secundários (Munn et al. 1999). Foi relatado por Dai \& Zhu (2010), que poucas células do baço de ratos expressavam a IDO, onde foi relatada a presença de aglomerados de pequenas células mononucleares dispersos na polpa vermelha (Mellor et al. 2003, Dai \& Zhu 2010). Os resultados deste estudo mostraram que as células IDO-positivas foram marcadas principalmente em regiões espalhadas na polpa vermelha, em particular na zona marginal localizada entre a polpa branca e a polpa vermelha circundante, contendo macrófagos e células reticulares (com funções de apresentação de antígeno), características estas também observadas neste trabalho.0 rim cefálico apresentou marcação para a IDO, principalmente no tecido hematopoiético e também nas glândulas interrenais e célu- las cromafins. Como se sabe, o rim cefálico é considerado um órgão primário diferenciador de células (Zapata 1981), além de ser o principal tecido hematopoiético, possuindo função endócrina e imunológica e atuando na produção de anticorpos e catecolaminas (Weyts et al. 1999), portanto, justifica a expressão da IDO em seu parênquima.

Nos teleósteos as células cromafins formam pequenas ilhas nas paredes das veias e, em algumas espécies, encontram-se dispersas nos rins cefálicos. Estas células desempenham funções equivalentes às das medulas adrenais em mamíferos. A biossíntese das catecolaminas ocorre através das células cromafins dos teleósteos e a inativação dessas moléculas ocorre pela via hepática e pelos rins antes de serem excretadas pela urina (Sens 2009).

Rocha et al. (2001) observaram que a glândula interrenal e as células cromafins estão interligadas e distribuídas no rim cefálico, como observado neste trabalho. Geralmente, a glândula interrenal consiste de grupos, cordões ou faixas de células, enquanto as células cromafins formam pequenos grupos, ambos inseridos muito próximos aos vasos sanguíneos. A excreção de corticosteroides, (cortisol) nas células interrenais e catecolaminas nas células cromafins, assim como a adrenalina e a noradrenalina, são consideradas as respostas primárias do estresse (Tavares-Dias 2001). Estudos realizados por Farias et al. (1989), demostraram que a morfologia do tecido interrenal e das células 
cromafins era frequentemente variável, mesmo quando se examinavam espécies de peixes filogeneticamente próximas. 0 fato das células interrenais e cromafins terem marcado positivamente pode estar relacionado à ação anti-inflamatória da IDO, como relata um estudo realizado em pacientes com doenças inflamatórias que observou que a célula T helper 1 (Th-1), IFN- $\gamma$ e o fator de necrose tumoral (TNF- $\alpha$ ) são fortes indutores da expressão de IDO (Wolf, Wolf \& Rumpold 2004) e que a expressão e suas atividades influenciam os mecanismos da ativação imune (Hainz et al. 2005).

Ao realizar os imprints com o rim cefálico foi possível observar mais claramente a marcação dos leucócitos, mais destacada nos monócitos e linfócitos que se apresentavam em diversos tamanhos e fases de maturação.

Nas extensões sanguíneas, observou-se marcação seletiva de alguns leucócitos, dentre eles monócitos e linfócitos. Segundo Tavares Dias \& Moraes (2004), os monócitos geralmente são caracterizados morfologicamente como células grandes e arredondadas, com núcleo em formato de "grão de feijão", citoplasma basofílico e vacuolizado, características observadas nos monócitos marcados pela IDO. Esta marcação positiva de monócitos leva-se a supor que as células que expressam a IDO possam estar em um estágio de maturação celular específico, ou que somente algumas células possuam receptores para IDO. Acreditamos que esta assertiva é verdadeira pelo fato de que em mamíferos nem todos os tipos de leucócitos expressam o mesmo nível de IDO (Wang et al. 2013). Alguns monócitos são estimulados pelo fator-estimulador-colônias de-macrófagos (MCSF) tornando-se macrófagos que suprimem a proliferação de células $T$ in vitro (Munn et al. 1999), fato que pode estar associado a um estágio específico de maturação. Munn et al. (1999) observou em seu estudo que os monócitos diferenciados sob a influência do fator estimulante da colônia de macrófagos adquiriram a habilidade de suprimir a proliferação de células T in vitro via rápida e seletiva degradação do triptofano pela IDO. Nos salmonídeos a grande quantidade de melano-macrófagos no rim cefálico é comum (Press et al. 1994), e são consideradas uma das células mais evidenciadas, que podem ser encontradas livres ou agrupadas no tecido (Costa 2007), porém não foi possível evidenciar se estes macrófagos também foram marcados pela IDO devido a sua coloração mascarar a reação do DAB na imuno-histoquímica. A contagem diferencial mostrou que a maioria das células que expressaram IDO era constituída por linfócitos. Sabe-se que a porcentagem de linfócitos circulantes em truta arco-íris é alta, variando entre 50 a $70 \%$ dos leucócitos (Houston et al. 1996). Outra evidência que comprova a marcação de linfócitos são suas características morfológicas onde as células apresentam-se predominantemente arredondadas de tamanhos variados, com projeções citoplasmáticas, sem granulações visíveis, núcleo com cromatina densa ocupando quase todo o citoplasma (Kfoury et al. 1999, Tavares-Dias \& Moraes 2004), características observadas neste trabalho.

Ao analisar as imagens ao microscópio de luz, pode-se observar a marcação positiva de alguns neutrófilos, que nos teleósteos são caracterizados pelo formato arredonda- do, núcleo geralmente na forma de bastonete e raramente apresentam-se na forma segmentada, com cromatina nuclear pouco compactada e sem nucléolo visível. 0 citoplasma é repleto de granulações acidofílicas (Tavares-Dias \& Moraes 2004). Os neutrófilos possuem grande quantidade de peroxidase, que promove a oxidação de certos compostos pelo peróxido de hidrogênio no processo de fagocitose, podendo aderir às células endoteliais e migrar para o foco inflamatório, atraídos por quimiotaxia (Iwama \& Nakanishi 1996). A marcação positiva pode ser devida à reatividade cruzada entre a peroxidase endógena dos neutrófilos e o DAB, podendo desta forma considerar estas células como falso positivas (Li et al. 1987). O primeiro bloqueio com peroxido (peróxido de hidrogênio e metanol), faz com que ocorra a inibição da peroxidase endógena, fazendo com que o DAB se ligue à biotina, marcando os grânulos de neutrófilos, promovendo um resultado falso positivo da célula, no entanto não se pode afirmar se estas células são falso positivas, ou se a marcação da IDO é verdadeira nesta célula.

No contexto geral, a IDO pode contribuir para limitar os mecanismos imunes efetores e prevenir a atividade imune exagerada ou gerar uma imunossupressão. Desta forma a atividade da IDO é considerada como tendo um potencial ambivalente podendo atuar em benefício ou detrimento do hospedeiro. A atividade imunológica da IDO pode ser vista como um mecanismo de feedback que contra regula a ativação imune (Munn 2006). Podemos supor que estes mecanismos possam existir em vertebrados inferiores como, por exemplo, na truta arco-íris, contudo para isso novas abordagens visando efetivamente investigar a ação da IDO nessa espécie são necessários. Este trabalho constituiu um primeiro passo para a elucidação desta hipótese.

\section{CONCLUSÃO}

Baseado nas observações durante a elaboração deste trabalho comprovou-se a marcação positiva da indoleamina 2,3-dioxigenase (ID01), nos órgãos hematopoiéticos (rim cefálico, baço, fígado), leucócitos (linfócitos, monócitos, neutrófilos) e glândula interrenal de truta arco-íris (Oncorhynchus mykiss).

Agradecimentos.- À FAPESP e APTA - Estação experimental de Salmonicultura.

\section{REFERÊNCIAS}

Barksdale A.R., Bernard A.C., Maley M.E. Gellin G.L., Kearney P.A., Boulanger B.R., Tsuei B.J. \& Ochoa J.B. 2004. Regulation of arginase expression by T-helper II cytokines and isoproterenol. Surgery 135(5):527-535.

Costa G.M. 2007. Estudo histomorfológico e análise dos perfis celulares do rim cefálico, fígado, baço e timo do Piaractus mesopotamicus (Holmberg, 1887, Teleósteo, characidade), pacu. Dissertação de Mestrado em Ciências, Faculdade de Medicina Veterinária e Zootecnia, Universidade de São Paulo, São Paulo. 134p.

Coyle S.D., Durborow R.W. \& Tidwell H.J. 2004. Anaesthetics in aquaculture. SRAC Publication, Southern Regional Aquaculture Center, USA, n.3900.

Dai X. \& Zhu B.T. 2010. Indoleamine 2,3-dioxygenase tissue distribution and cellular localization in mice: implications for its biological functions. J. Histochem. Cytochem. 58(1):854-860.

Farias E.C., Alexandrino A.C., Pinheiro E.F.G. \& Borella M.I. 1989. Histologia do tecido inter-renal e das células cromafins de curimbatá, Prochilodus 
scrofa Steindachner, Pisces Cypriniformes durante o ciclo reprodutivo. Revta Fac. Med. Vet. Zootec. USP 26(1):7-13.

Fletcher T.C. 1981. Non-antibody molecules and the defense mechanisms of fish, p.171-183. In: Pickering A.D. (Ed.), Stress and Fish. Academic Press, New York.

Garcia-Leme J. 1989. Hormones and inflammation. CRC Press, Boca Raton. 238p.

Hainz U., Obexer P. \& Winkler C. 2005. Monocyte-mediated T-cell suppression and augmented monocyte tryptophan catabolism after human hematopoietic stem-cell transplantation. Blood 105:4127.

Houston A.H., Dobric N. \& Kahurananga R. 1996. The nature of hematological response in fish. Fish Physiol. Biochem. 15(4):339-347.

Kfoury Jr J.R., Kuroda A., Nakayasu C., Fukuda H. \& Okamoto N. 1999. Analysis of raimbow trout peripheral blood leucocytes separated by flow cytometry cell sorting. Fish Pathol. 34(1):1-6.

Li C.Y., Ziesmer S.C. \& Lazcano-Villareal O. 1987. Use of azide and hydrogen peroxide as an inhibitor for endogenous peroxidase in the immunoperoxidase method. J. Histochem. Cytochem. 35(12):1457-1460.

Matushima E.R. 1988. Cinética da reação inflamatória induzida pela carragenina na bexiga natatória de Oreochromis niloticus (Tilápia do Nilo). Dissertação de Mestrado, Faculdade de Medicina Veterinária e Zootecnia, Universidade de São Paulo, São Paulo. 53p.

Mellor A.L., Baban B., Chandler P. Marshall B., Jhaver K., Hansen A., Koni P.A., Iwashima M. \& Munn D.H. 2003. Cutting edge: induced indoleamine 2,3 dioxygenase expression in dendritic cell subsets suppresses $\mathrm{T}$ cell clonal expansion. J. Immunol. 171:1652-1655.

Munn D.H. 2006. Indoleamine 2,3-dioxygenase, tumor-induced tolerance and counter-regulation. Curr. Opinion Immunol. 18:220.

Munn D.H., Sharma M.D., Hou D., Baban B., Lee J.R., Antonia S.J., Messina J.L., Chandler P., Koni P.A. \& Mellor A.L. 2004. Expression of IDO by plasmacytoid dendritic cells in tumor-draining lymph nodes. J. Clin. Invest. 114(2):280-290.

Munn D.H., Sharma M.D. \& Lee J.R. 2002. Potential regulatory function of human dendritic cells expressing indoleamine 2,3-dioxygenase. Science 297:1867-1870.

Munn D.H., Shafizadeh E., Attwood I.B., Pashine A. \& Mellor A.L. 1999. Inhibition of T cell proliferation by machophage tryptophan catabolism. J. Exp. Med. 189(9):1363-1372.

Munn D.H., Zhou M., Attwood J.T., Bondarev I., Conway S.J., Marshall B., Brown C. \& Mellor A.L. 1998. Prevention of allogenic fetal rejection by tryptophan catabolism. Science 281(5380):1191-1193.

Press C.M.L., Dannevig B.H. \& Landsverk T. 1994. Immune and enzyme histochemical phenotypes of lymphoid and non lymphoid cells the spleen and head kidney of Atlantic Salmon (Salmo salar). Fish Shellfish Biol. 4:79-93.

Rocha R.M., Santos L.H.S., Vicentini C.A. \& Cruz C. 2001. Structural and ultrastructural characteristics of interrenal gland and chromaffin cell of Matrinxã, Brycon cephalus Gunther (Teleostei-Characidae). Anat. Histol. Embryol. 30:351-355.

Secombes C.J. 1996. The nonspecific immune system: celular defensas. In: Iwama G. \& Nakanishi T. (Eds), The Fish Immune System. Academic Press, London, p.63-105.
Shoemaker C.A., Klesius P.H. \& Lim C. 2001. Immunity and disease resistance in fish, p.149-162. In: Lim C. \& Webster C.D. (Eds), Nutrition and Fish Health. Food Products Press, New York.

Sens D.R. 2009. Efeitos do triclorfom no crescimento e parâmetros hematológicos de tambaquis (Colossoma macropomum). Dissertação de Mestrado, Universidade Federal do Tocantins, Palmas. 60p.

Snedecor G.W. \& Cochran G. 1974. Statistical Methods. Iowa State University Press, Ames.

Takikawa O., Yoshida R., Kido R. \& Hayaishi O. 1986. Tryptophan degradation in mice initiated by indoleamine 2,3-dioxygenase. J. Biol. Chemistry 261(8):3648-3653.

Tavares-Dias M. \& Moraes F.R. 2004. Hematologia de Peixes Teleósteos. Vilimpress, Ribeirão Preto. 144p.

Tavares-Dias M., Sandrim E.F.S., Moraes F.R. \& Carneiro P.C.F. 2001. Physiological responses of "tambaqui" Colossoma macropomum (Characidae) to acute stress. Bolm Inst. Pesca, São Paulo, 27:43-48.

Thomas R.S. \& Stocker R. 1999. Redox reactions related to indoleamine 2,3-dioxygenase and tryptophan metabolismo along the kynurenine pathway. Redox Report 4(5):199-220.

Wang N.L., Zhang W.J., Duan J.Z. \& Yang G.B. 2013. Indoleamine 2,3-dioxygenase is differentially expressed by different white blood cell populations of rhesus macaques (Macaca mulatta). J. Med. Primatol., doi: 10.1111/jmp.12054.

Wedemeyer G. 1970. Stress of anesthesia with MS-222 and benzocaine in rainbow trout (Salmo gairdneri). J. Fish. Res., Board of Canada, 22(5): 909-914.

Weyts F.A.A., Cohen N., Flink G. \& Verburg B.M.L. 1999. Interactions between the immune system and the hypothalamo-pituitary-interrenal axis in fish. Fish and Shellfish Immunol. 9:1-20.

Wolf A.M., Wolf D. \& Rumpold H. 2004. Overexpression of indoleamine 2,3-dioxygenase in human inflammatory bowel disease. Clin. Immunol. 113:47-55.

Yuasa H.J., Ball H.J., Ho Y.F., Austin C.J.D., Whittington K.B., Maghzal G.J., Jermiin L.S. \& Hunt N.H. 2009. Characterization and evolution of vertebrate indoleamine 2,3-dioxygenases IDOs from monotremes and marsupials. Comp. Biochem. Physiol. B 153:137-144.

Yuasa H.J. \& Ball H.J. 2012. The evolution of three types of indoleamine 2,3-dioxygenases in fungi with distinct molecular and biochemical characteristics. Gene 504:64-74.

Yuasa H.J., Tabuco M., Takahashi A., Hasegawa T., Noma H. \& Suzuki T. 2007. Evolution of vertebrate indoleamine 2,3-dioxygenases. J. Mol. Evolution 65:705-714.

Yuasa H.J., Ushigoe A. \& Ball H.J. 2011. Molecular evolution of bacterial indoleamine 2,3-dioxygenase. Gene 485:22-31.

Zapata A.G. 1981. Lymphoid organs of teleost fish. II. Ultrastructure of renal lymphoid tissue of Rutilus rutilus and Gobio gobio. Develop. Comp. Immunol. 5(4):685-690.

Zapata A.G., Chibá A. \& Varas A. 1996. Cells and tissues of the imune system of fish, p.1-62. In: Iwana G. \& Nakanishi T. (Eds), The Fish Immune System: organism, pathogen and evironment. Vol.15. Academic Press, San Diego, 380p. 